\title{
MODELO CAPES dE AVALIAÇÃO: \\ QUAIS AS CONSEQUÊNCIAS PARA O TRIÊNIO 2010-2012?
}

THE CAPES ASSESSMENT MODEL:

WHAT WILL THE CONSEQUENCES BE FOR THE TRIENNIUM 2010-2012?

LUIS FELIPE NASCIMENTO (nascimento@ea.ufrgs.br)

UNIVERSIDADE FEDERAL DO RIO GRANDE DO SUL

\section{RESUMO}

Este artigo tem por objetivo analisar o sistema de avaliação dos programas de pós-graduação na Área de Administração, Ciências Contábeis e Turismo da CAPES (Coordenação de Aperfeiçoamento de Pessoal de Nível Superior) e propor medidas para aprimorar estas avaliações. Induzidos pelos critérios de avaliação da CAPES, os programas de pós-graduação passaram a supervalorizar a produção científica em detrimento das demais atividades desenvolvidas pelos seus professores. O fator de impacto, medida que indica a qualidade dos periódicos, transformou-se no indicador da qualidade do trabalho do professor, uma vez que as avaliações individuais dos professores estão fortemente centradas na análise da sua produção científica. Para atingir o objetivo proposto foi realizada uma revisão na literatura sobre avaliação na pós-graduação, que, juntamente com a experiência do autor como professor, pesquisador, gestor de programa de pós-graduação e também membro em 2007 da comissão que avaliou o desempenho dos programas de pós-graduação em Administração subsidiaram a análise aqui apresentada. O artigo apresenta questionamentos e algumas propostas. Questionam-se os atuais critérios de avaliação do desempenho individual dos professores e alerta-se para suas possíveis consequências. Sugere-se que a avaliação considere todas as atividades desenvolvidas pelo professor, construindo o que foi denominado pelo autor de Fator "P". Este Fator mediria o impacto das atividades do professor no âmbito local, nacional e internacional. Nas considerações finais, é feito um convite para que os membros da comunidade científica se engajem no debate destas questões.

Palavras-Chave: avaliação CAPES; fator de impacto; avaliação professores, triênio 2010-2012. 
ABSTRACT

This article aims to investigate the system used by CAPES (Coordination of Training Higher Education Staff) to assess the individual members of the academic staff engaged in post-graduate programs in Business, Accounting and Tourism and propose measures to improve the assessment process. Induced by the assessment criteria employed by CAPES, post-graduate programs began to overvalue scientific production, attributing little or no value to other activities undertaken by the academic staff. The impact factor, which reflects the quality of journals, has become the indicator of the quality of a teacher's work since professor assessment is strongly focused on the analysis of scientific output. This article is based on the author's experience a teacherresearcher, coordinator and evaluator of post-graduate programs. Among other proposals, it is suggested that a "P" factor be created in order to measure the impact of the teacher's activities at the local, national and international levels. This represents an open invitation to members of the scientific community to discuss these issues.

Keywords: CAPES assessment; impact factor; professor assessment; triennium 2010-2012.

\section{INTRODUÇÃO}

Este artigo tem por objetivo analisar e propor uma reflexão sobre os critérios de avaliação individual dos professores dos programas de pósgraduação das universidades brasileiras.

As atividades de pesquisa no Brasil estão concentradas nos cursos e programas de pós-graduação das universidades, mas nestas instituições não existe a função única de pesquisador, cabendo aos professores da pósgraduação desempenhar as funções de docente e de pesquisador, bem como outras atividades, como, por exemplo: assumir funções administrativas, de extensão e de representação. Neste artigo será empregado o termo "professor" para referir-se à pessoa que assume todas as funções acima citadas.

Nos últimos anos houve incrementos importantes no sistema de avaliação da Coordenação de Aperfeiçoamento de Pessoal de Nível Superior (CAPES), tendo sido dada maior ênfase para a produção científica dos programas, e, mais especificamente, à publicação de artigos 
em periódicos científicos. A pontuação atribuída aos artigos apresentados em eventos científicos foi sendo reduzida e não é mais valorizada no triênio 2010-2012. Isso decorre, segundo representantes da CAPES em palestra realizada na UFRGS e em eventos sobre o processo de avaliação, de um artigo apresentado em um evento científico, que está em fase de aperfeiçoamento, cujo autor pretende incorporar as críticas e sugestões recebidas nestes eventos, para, então, submetê-lo a um periódico. Portanto, o projeto de pesquisa, a dissertação, a tese, que deram origem ao artigo apresentado em um evento, são etapas de um processo, que terá como produto final o artigo publicado num periódico.

Considerando as dificuldades para a avaliação do "processo", a CAPES adotou a política de valorização do "produto final". A qualidade do produto final, o artigo científico, será atestada pelos referees do periódico ao qual este artigo for submetido, e a qualidade do periódico será indicada pelo fator de impacto deste periódico ${ }^{(*)}$.

Cabe ressaltar que a CAPES não avalia o desempenho individual dos professores e sim o desempenho dos programas de pós-graduação. Mas, na prática, são os critérios da CAPES que mais pressionam o professor a aumentar seu desempenho individual, como por exemplo, os estabelecidos na Portaria $n^{\circ} 068$, de 03 de agosto de 2004, onde estão estabelecidos os pré-requisitos para que os professores se enquadrem como "docentes permanentes" de um curso de pós-graduação.

Os critérios estabelecidos pelo Comitê Técnico Científico (CTC) da CAPES, que tem o papel de harmonizar os critérios de avaliação, foram assimilados pelas suas 47 áreas de conhecimento, pelas universidades por meio de suas Câmaras de Pós-Graduação ou similares e por mais de 4000 cursos de pós-graduação distribuídos pelo Brasil.

A exigência de pontuação mínima no quesito de produção científica fez com que alguns programas seguissem a política de publish or perish, ou seja, publique ou deixe de ser professor do núcleo de docentes permanentes (NDP) do Programa.

A pressão para que os professores publiquem em periódicos tem gerado alto nível de estresse, alterado as prioridades, e as consequências de médio e longo prazo não foram ainda dimensionadas. A tendência é a adaptação dos professores aos critérios, reduzindo sua dedicação às atividades menos ou não pontuadas, ou ainda deixando de exercer tais atividades.

\footnotetext{
${ }^{(*)}$ Fator de Impacto é a medida utilizada pelo Journal Citation Report (JCR), de propriedade da Empresa Thompson-Reuter, para classificar os periódicos científicos. Existem outras organizações que também classificam os periódicos em função da sua importância acadêmica.
} 
Quais serão as consequências da política de valorização do produto em detrimento do processo? Como irão reagir os professores no triênio 2010-2012 diante de atividades que lhes são solicitadas, mas que não são valorizadas na sua avaliação individual? Visando discutir estas questões, foram desenvolvidas seis sessões neste artigo. Na próxima sessão é realizado um histórico da pós-graduação e da pesquisa nas universidades brasileiras; na segunda sessão é feita uma revisão na literatura sobre as críticas ao modelo CAPES de avaliação; na sessão seguinte é discutido o descolamento entre a avaliação do programa e a avaliação individual do professor. Na quarta sessão, com base na revisão da literatura sobre o modelo CAPES de avaliação, o autor propõe revisões nos critérios de avaliação. Na quinta sessão é apresentada a proposta do Fator "P", para medir o impacto de todas as atividades desenvolvidas pelo professor. Na última sessão, são apresentadas as conclusões finais.

\section{A Pós-GraduaÇão e a Pesquisa nas Universidades Brasileiras}

Fazendo um breve histórico sobre a relação do ensino na pós-graduação com a pesquisa, pode-se dizer que a educação superior no Brasil iniciouse com a criação de faculdades isoladas, as quais, posteriormente, foram reunidas para formar as universidades. Nesta época, a pesquisa era desenvolvida em institutos fora das universidades.

Ocorreram várias tentativas para associar o ensino e a pesquisa nas universidades, como, por exemplo, a criação da Faculdade de Filosofia, Ciências e Letras da USP e as propostas inovadoras da UNB, com Darcy Ribeiro e Anísio Teixeira, experiências estas que não conseguiram se consolidar na época (HAMBURGER,1980).

A origem da pós-graduação no Brasil, segundo Sguissardi (2006), ocorreu na década de 1930; entretanto, o atual sistema de pós-graduação foi estruturado entre os anos de 1965 e 1970. A pós-graduação importou modelos de Portugal, França, Alemanha e, por último, o modelo Americano. Segundo Hamburger (1980), o modelo europeu que prevalecia no Brasil não exigia muitos créditos, nem exames de qualificação e de línguas; eram exigidos apenas dois exames e a tese para a obtenção do título de doutor. Com a implantação do modelo americano, passou a vigorar o sistema de créditos e demais requisitos utilizados ainda hoje pelos programas de pós-graduação.

Segundo Hamburger (1980), o governo brasileiro implantou três medidas sincronizadas que foram fundamentais para o fortalecimento da 
pós-graduação: a) a estrutura de carreira universitária, exigindo pósgraduação dos professores; b) o financiamento dos programas de pósgraduação e pesquisa pelo BNDES, CNPq, FINEP, CAPES e outros órgãos; c) a regulamentação acadêmica, iniciada com o parecer Sucupira (Parecer n. 977/65 - Definição dos Cursos de Pós-Graduação, de autoria de Newton Sucupira, do extinto Conselho Federal de Educação), que, de forma geral, segue a regulamentação das universidades americanas. Com a aprovação da Lei 5.540/68 (Reforma Universitária), ficou estabelecida a obrigatoriedade da associação entre ensino e pesquisa; mas, pela forma como foi implantada, não atingiu os objetivos esperados. Em algumas faculdades, a pós-graduação permaneceu por vários anos como um corpo estranho. Hamburger (1980) relata que, desde o início do sistema de pósgraduação, foi colocado como objetivo primeiro a publicação em revistas internacionais.

Em 1974, foi criado o Conselho Nacional de Pós-Graduação e, em 1975, foi lançado o Plano Nacional de Pós-Graduação. No site da CAPES, consta que o Sistema de Avaliação da Pós-graduação foi implantado pela CAPES em 1976. Segundo Sguissardi (2006), o "Modelo CAPES de Avaliação" foi implantado a partir de 1996-97, gerando muitas análises e reflexões de especialistas sobre este novo modelo.

\section{O Modelo CAPES de Avaliação}

Não se tem informação de que exista outro país com um sistema de avaliação institucional como o da CAPES. O banco de currículos da Plataforma Lattes, o Sistema Qualis são conquistas brasileiras sem similar no exterior. Nos meses de julho e agosto de 2010, foi realizada a avaliação trienal da pós-graduação (período de 2007 a 2009). Deste processo participaram cerca de 900 pesquisadores, que, entre outras atividades, utilizaram o Qualis para avaliar 270 mil artigos publicados em mais de 17 mil diferentes periódicos (FOLHA DE SÃO PAULO, 2010).

O sistema de pós-graduação brasileiro cresceu em número e em qualidade nas últimas décadas. Os cursos de pós-graduação se adequaram às novas regras, pressionados por vários fatores, principalmente pelo modelo CAPES de avaliação, embora este modelo seja questionado em diferentes aspectos, por vários autores.

A padronização entre as áreas não é considerada adequada por Spagnolo e Calhau (2002), que justificam que existe heterogeneidade nas 
áreas do saber e nas instituições em relação aos recursos e às condições econômicas. Alegam que a homogeneidade nunca foi um atributo de grupos de cientistas.

Kuenzer e Moraes (2005) fazem considerações sobre a ênfase na produção acadêmica. Consideram que as exigências por produção acadêmica resultaram num surto produtivista, não importando se a publicação é uma versão requentada ou maquiada; o importante é publicar.

Neste sentido, Sguissardi (2006) pergunta: quais consequências para a educação superior que trará um modelo de avaliação que privilegia a formação do pesquisador mensurando quantitativamente sua produção científica, em detrimento de uma formação integral do pós-graduando? Que lugar ocupa neste modelo a autoavaliação, a avaliação educativa ou a diagnóstico-formativa?

Dias Sobrinho (2003a) propõe a desvinculação do processo de avaliação da possibilidade de punição e premiação. Em sua opinião, a avaliação deve ser formativa, não tendo, portanto, como principal função o controle. A avaliação deveria estar desvinculada das medidas de financiamento, premiação ou punição, e também da produção de rankings.

Moreira, Hortale e Hartz (2004) sugerem que o modelo de avaliação adotado pela CAPES está mais orientado para a pesquisa do que para a qualidade do ensino. Consideram muito discutível entender a pesquisa e as publicações que dela (a pesquisa) são derivadas como evidências da qualidade do ensino. Estes autores afirmam que a formação de qualidade exige competências pedagógicas e científicas, que, nem sempre, são resultantes das atividades de pesquisa.

Quanto ao papel das universidades na sociedade, Dias Sobrinho (2003) distingue as "organizações sociais" das "instituições sociais". As organizações sociais adaptam os meios aos fins a que se destinam, visando a obter um resultado prático. Neste caso, a eficiência se torna uma finalidade em si, sendo adequada uma avaliação como regulação e controle. Já uma instituição social - uma universidade, por exemplo, que tem como finalidade o desenvolvimento dos valores da sociedade - deve ter uma avaliação que promova a reflexão e o questionamento.

Referindo-se aos indicadores utilizados pela CAPES, Spagnolo e Calhau (2002) alertam para o fato de que professores e coordenadores de programas trabalham visando aos indicadores que têm maior peso na avaliação da CAPES, o que não implicaria necessariamente na melhoria da qualidade dos respectivos programas. Algumas universidades 
aprenderam bem a lição: “dar à CAPES o que ela quer", ou seja, para elevar o conceito de um programa de pós-graduação, é preciso organizar o programa conforme as regras do modelo CAPES de avaliação. Estes questionamentos são contestados pelos dirigentes da CAPES ao afirmarem que é equivocada e distorcida a ideia de que avaliação da pósgraduação é exclusivamente um processo para "avaliar o quantitativo da produção intelectual” (FOLHA DE SÃO PAULO, 2010).

\section{Avaliação do Individual versus Avaliação do Programa de Pós-GraduAÇÃo}

Muitas são as avaliações dos professores da pós-graduação stricto sensu nas universidades públicas e não públicas: individuais internas e externas; como parte de um departamento; como membro de um programa de pósgraduação; no nível da Câmara de Pós-Graduação ou órgão similar; por mecanismos do CNPq; e mecanismos de outros órgãos financiadores de projetos.

No caso das universidades públicas, o professor passa por uma avaliação do seu departamento, em que são atribuídos pontos para o seu desempenho em sala de aula, orientações, carga horária cumprida no período, publicações, entre outros indicadores. Esta pontuação faz parte do mecanismo de progressão funcional. Uma análise dos resultados destas avaliações mostra que os professores dos programas de pós-graduação, com raras exceções, obtêm a pontuação mínima exigida. A avaliação para progressão funcional torna-se mais uma barreira burocrática do que uma avaliação para medir desempenho, uma vez que os índices exigidos são facilmente atingidos. As universidades não públicas adotam critérios próprios de avaliação.

Os programas de pós-graduação estabelecem metas e critérios internos para a inclusão ou exclusão de professores, nas categorias de permanentes ou de colaboradores, seguindo as orientações da CAPES (Portaria $n^{\circ} 068$ de 03.08.2004). Programas que almejam conceitos mais elevados na CAPES costumam ser mais rigorosos na avaliação dos seus professores, como forma de refletir seu padrão médio de atuação.

Uma terceira avaliação interna, que ocorre nas universidades públicas e em algumas não públicas, é a avaliação realizada pelas Câmaras de Pós-Graduação, ou outros órgãos com funções semelhantes. Esta avaliação visa ao credenciamento e ao recredenciamento dos professores nos programas de pós-graduação da respectiva universidade. 
A Câmara de Pós-Graduação adota os critérios da CAPES, mas por conhecer as especificidades de cada programa costuma ser mais flexível. O coordenador de um programa poderá justificar perante a Câmara de Pós-Graduação que determinado professor não atende a algum requisito, mas que seu credenciamento ou recredenciamento é importante para o programa. Tais justificativas costumam ser aceitas pelas Câmaras visando a não prejudicar os programas.

Externamente à universidade, os professores são avaliados todas as vezes que submetem projetos ou solicitam recursos e bolsas a órgãos como CAPES, CNPq, Fundações Estaduais de Apoio à Pesquisa, organismos internacionais, entre outras possibilidades. Nestes casos, as avaliações consideram a produção científica e os itens que são salientados nos respectivos editais.

O Quadro 1 apresenta as atividades desejáveis de serem desenvolvidas pelos professores ao longo de um triênio. A Portaria $\mathrm{n}^{\circ}$ 068 (03.08.2004) da CAPES estabelece, entre outros itens, que o professor, para se enquadrar como docente permanente deve: desenvolver atividades de ensino na pós-graduação e/ou graduação; participar de projeto de pesquisa do programa; orientar alunos de mestrado ou doutorado do programa, sendo devidamente credenciado como orientador pela instância para esse fim considerada competente pela instituição. No Art. $2^{\circ}$, Item $\mathrm{V}, \S 3^{\mathrm{o}}$ consta:

A estabilidade de docentes permanentes do programa será objeto de acompanhamento e de avaliação sistemáticos pela CAPES, sendo requerido às instituições justificar as ocorrências de credenciamentos e descredenciamentos de integrantes dessa categoria verificadas de um ano para outro.

A avaliação individual da CAPES segue critérios semelhantes aos do CNPq, para a concessão de bolsas e apoios. A avaliação institucional dos programas de pós-graduação é realizada ao final de cada triênio pela Comissão de Área (CA). Como a CAPES não possui comissões fixas, essas são formadas quando é necessário desenvolver uma tarefa específica. Nestas ocasiões, são convidados consultores obedecendo aos seguintes requisitos: qualificação e competência técnico-científica (Bolsa CNPq, nível 1, se possível); desempenho acadêmico do programa a que se vincula o consultor (nota 4, se possível); cobertura das áreas e subáreas das propostas ou dos programas da Área; equilíbrio na representação regional e de IES; renovação de participantes, sendo respeitada a necessidade de participarem da comissão consultores com experiência na 
Avaliação; adequação do número de integrantes ao total de programas e à diversidade de áreas e subáreas.

Os resultados da avaliação de cada área são encaminhados para o Comitê Técnico Científico (CTC) da CAPES, que é formado por 24 membros: o Presidente da Capes; três diretores (de Avaliação, de Programas e Bolsas no País e de Relações Internacionais); 18 representantes das grandes áreas; um representante do Foprop e um representante da ANPG (doutorando). O CTC é quem regulamenta, ordena e coordena todo o processo de avaliação dos programas de pósgraduação no Brasil, ou seja, quem dá a palavra final sobre os pareceres das Comissões de Área.

A avaliação institucional foi sendo aprimorada nos últimos anos e é realizada pelos próprios programas por meio da inclusão dos seus dados num software conhecido como "Coleta CAPES". Os programas devem preencher a ficha de avaliação, que é composta por cinco quesitos: I Proposta do Programa - sem atribuição de peso; II - Corpo Docente peso de $20 \%$ sobre o total da avaliação; III - Corpo discente, teses e dissertações - peso de 35\%; IV - Produção Intelectual - peso de 35\%; e V - Inserção social - peso $10 \%$. Cada um destes quesitos é subdividido em uma série de itens, apresentados na Figura 1. Existe uma pequena margem de variação no peso de cada quesito, que faz com que algumas áreas valorizem mais ou menos cada um dos quesitos. Esta variação poderá ocorrer na mesma área, de um trimestre para outro. Por exemplo, a área de Saúde Coletiva adotou alguns pesos diferentes aos quesitos, atribuindo à Proposta do Programa $=0$, Corpo docente $=15 \%$, Corpo discente, teses e dissertações $=30 \%$, Produção Intelectual $=40 \% \mathrm{e}$ Inserção Social $=15 \%$. 
Figura 1: Critérios de Avaliação da Área de Administração, Contábeis e Turismo 2007-2009

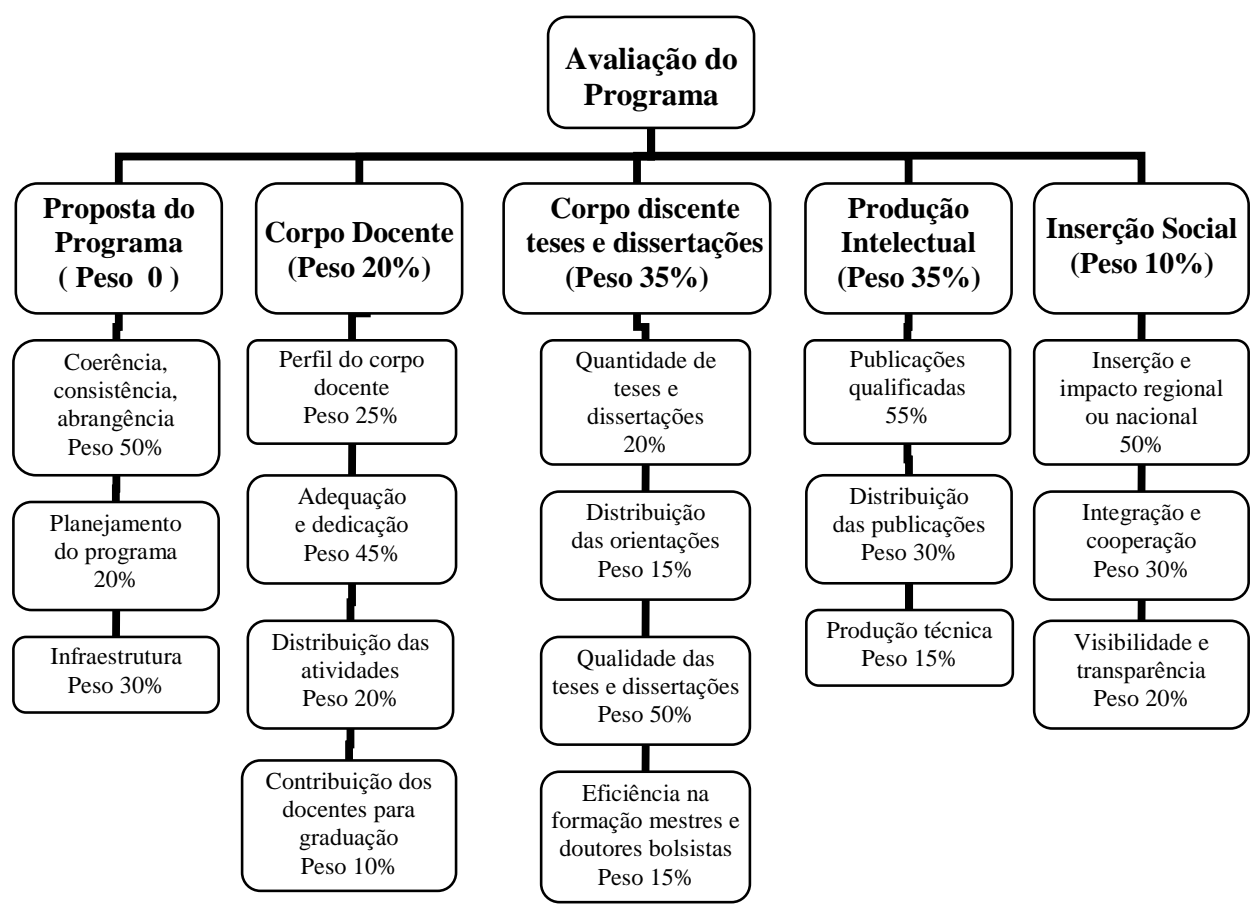

Fonte: Adaptado do Documento de Área Administração, Ciências Contábeis e Turismo (2009).

Todas as atividades realizadas pelos professores, durante o triênio são valorizadas na avaliação do programa. O Quadro 1 foi elaborado pelo autor, relacionando os quesitos e as atividades que são consideradas desejáveis, pela CAPES e CNPq, de serem realizadas pelos professores ao longo de um triênio. O desenvolvimento dos 17 quesitos contribui positivamente para a avaliação do programa, mas o último - publicar artigos em periódicos de alto impacto - é o mais valorizado para a avaliação individual do professor. Numa situação hipotética, um professor poderia obter ótimo desempenho nos primeiros 16 quesitos e contribuir significativamente para o programa. Porém, se este professor não tiver os pontos necessários em publicações em periódicos, em especial periódicos de alto impacto (quesito 17), passaria a ser colaborador ou seria descredenciado do seu programa, pois sua permanência prejudicaria a avaliação do programa pela CAPES. 
Existe um descolamento entre o que é importante para o programa e o que é importante para o professor que pretende continuar atuando na pós-graduação. No triênio 2007-2009, os professores de programas considerados de excelência perceberam que a publicação de artigos em periódicos de alto impacto (A1, A2, B1 e B2) é o indicador de qualidade, que garante a sua permanência como professores do núcleo permanente destes programas. Se os primeiros 16 quesitos não são determinantes na avaliação individual do professor, será que os professores estarão motivados a desenvolver tais atividades no triênio 2010-2012? E se os professores da pós-graduação perderem o interesse pelas atividades internas e externas ao programa, quem desenvolverá tais atividades? As comissões de pesquisa serão formadas por professores que não fazem pesquisa? As câmaras de pós-graduação serão formadas por professores que não participam da pós-graduação? Os artigos submetidos aos periódicos serão avaliados por pesquisadores menos experientes?

Cabe esclarecer que os critérios da CAPES de avaliação do desempenho do professor diferem dos critérios do $\mathrm{CNPq}$ em alguns quesitos e se complementam em outros. Por exemplo, a CAPES definiu os requisitos para um professor pertencer ao núcleo de docentes permanentes (NDP) de um programa de pós-graduação (portaria $\mathrm{n}^{\circ}$ 68/2004, modificada pela portaria CAPES n $\left.{ }^{\circ} 3 / 2010\right)$. O CNPq adota como um dos requisitos para a concessão da bolsa de produtividade em pesquisa (PQ), que o candidato seja membro do NDP de um programa de pós-graduação.

Professores nas universidades não públicas não possuem a mesma flexibilidade de seus pares nas públicas, mas, mesmo assim, poderão facilmente encontrar boas justificativas para deixar de participar de atividades que não lhes somarão pontos, tais como as bancas de dissertação, tese ou de concursos para professores. Nas universidades públicas, já se percebe alguma dificuldade para encontrar candidatos a cargos administrativos, à orientação de aluno de graduação, a membro de comissões e a comitês da universidade, entre outras atividades. Exemplo disto é que ocorreu em 2008 nas eleições de uma unidade de uma universidade pública conceituada, onde algumas comissões não tiveram o número mínimo de candidatos para completar as nominatas, sendo necessária a realização de uma segunda eleição. Isto é compreensível, pois tais atividades demandam várias horas ou dias de trabalho, e não irão somar pontos na avaliação individual do docente. 
Quadro 1: Atividades desejáveis de serem desenvolvidas pelos professores ao longo de um triênio

\begin{tabular}{|c|c|}
\hline Quesito & Níveis/Atividades \\
\hline $\begin{array}{l}\text { 1. Ser docente em } \\
\text { cursos presenciais e } \\
\text { à distância }\end{array}$ & $\begin{array}{l}\text { Graduação } \\
\text { Extensão } \\
\text { Especialização } \\
\text { Mestrados acadêmico/profissional (*) } \\
\text { Doutorados }(*) \\
(*) \text { Na sede ou fora da sede (Minter, Dinter) }\end{array}$ \\
\hline $\begin{array}{l}\text { 2. Desenvolver } \\
\text { ações de extensão }\end{array}$ & $\begin{array}{l}\text { Palestras } \\
\text { Interações com a comunidade } \\
\text { Comitês Técnicos } \\
\text { Associações Científicas } \\
\text { Associações Empresariais }\end{array}$ \\
\hline $\begin{array}{l}\text { 3. Ser orientador em } \\
\text { diferentes níveis }\end{array}$ & $\begin{array}{l}\text { Graduação } \\
\text { Mestrado } \\
\text { Doutorado } \\
\text { Pós-Doutorado }\end{array}$ \\
\hline $\begin{array}{l}\text { 4. Participar de } \\
\text { bancas }\end{array}$ & $\begin{array}{l}\text { Graduação } \\
\text { Especialização } \\
\text { Mestrado } \\
\text { Doutorado } \\
\text { Concurso para Professor } \\
\end{array}$ \\
\hline $\begin{array}{l}\text { 5. Atuar junto a } \\
\text { periódicos }\end{array}$ & $\begin{array}{l}\text { Editor } \\
\text { Membro de Comitês Editoriais de revistas nacionais e intern. }\end{array}$ \\
\hline $\begin{array}{l}\text { 6. Ser avaliador } \\
\text { (referee) }\end{array}$ & $\begin{array}{l}\text { Avaliar artigos de Congressos } \\
\text { Avaliar artigos de Revistas }\end{array}$ \\
\hline $\begin{array}{l}\text { 7. Atuar como } \\
\text { consultor } a d \text { hoc }\end{array}$ & $\begin{array}{l}\text { Agências nacionais (projetos de pesquisa, auxílios financeiros, } \\
\text { etc.) } \\
\text { De agências internacionais }\end{array}$ \\
\hline $\begin{array}{l}\text { 8. Colaborar com } \\
\text { outras instituições } \\
\text { de ensino superior }\end{array}$ & $\begin{array}{l}\text { Instituições Nacionais (Casadinho, PROCAD, etc) } \\
\text { Instituições Internacionais (Convênios, pesquisador ou } \\
\text { professor visitante, intercâmbio de alunos, cotutela, pesquisa } \\
\text { conjunta etc) }\end{array}$ \\
\hline $\begin{array}{l}\text { 9. Obter premiações } \\
\text { e distinções }\end{array}$ & $\begin{array}{l}\text { Melhor artigo em eventos } \\
\text { Menções honrosas } \\
\text { Pesquisador destaque } \\
\text { Contribuições relevantes }\end{array}$ \\
\hline $\begin{array}{l}\text { 10. Organizar } \\
\text { eventos }\end{array}$ & $\begin{array}{l}\text { Organização de eventos nacionais } \\
\text { Organização de eventos internacionais (de boa qualidade) }\end{array}$ \\
\hline $\begin{array}{l}\text { 11. Participar em } \\
\text { entidades científicas }\end{array}$ & $\begin{array}{l}\text { Participação em diretoria ou da coordenação } \\
\text { Comitês de entidades científicas e de fomento }\end{array}$ \\
\hline $\begin{array}{l}\text { 12. Assumir cargos } \\
\text { Administrativos }\end{array}$ & $\begin{array}{l}\text { Comissões } \\
\text { Chefias } \\
\text { Coordenações } \\
\text { Diretor } \\
\text { Pró-Reitor }\end{array}$ \\
\hline
\end{tabular}




\begin{tabular}{|c|c|}
\hline & Reitor \\
\hline \multirow{3}{*}{$\begin{array}{c}\text { 13. Obter } \\
\text { experiência e } \\
\text { reconhecimento }\end{array}$} & Bolsas de produtividade em pesquisa \\
\hline & Estágios de pós-doutoramento \\
\hline & Projeção nacional e internacional \\
\hline \multirow{4}{*}{$\begin{array}{l}\text { 14.Desenvolver } \\
\text { produção técnica }\end{array}$} & Relatórios de serviços técnicos, \\
\hline & Consultorias e projetos executados \\
\hline & Pareceres e perícias técnicas \\
\hline & Planos elaborados, devidamente documentados \\
\hline \multirow{9}{*}{$\begin{array}{l}\text { 15. Produção } \\
\text { tecnológica }\end{array}$} & Casos \\
\hline & Materiais de ensino presencial e à distância \\
\hline & Patentes depositadas e registradas \\
\hline & Modelos de gestão \\
\hline & Modelos de análise de dados e informações \\
\hline & Instrumentos padronizados de coleta de dados \\
\hline & Tecnologias de processo e de produto \\
\hline & Aplicativos \\
\hline & $\begin{array}{l}\text { Marcas e softwares desenvolvidos com ou sem registro no } \\
\text { INPI. }\end{array}$ \\
\hline \multirow{4}{*}{$\begin{array}{l}\text { 16. Publicar livros e } \\
\text { capítulos }\end{array}$} & Autor \\
\hline & Coautor \\
\hline & Organizador \\
\hline & Publicação de capítulos \\
\hline \multirow{3}{*}{$\begin{array}{l}\text { 17. Publicar artigos } \\
\text { em periódicos }\end{array}$} & Revistas Nacionais \\
\hline & Revistas Internacionais \\
\hline & (Produção de alto impacto: A1, A2, B1, B2) \\
\hline
\end{tabular}

\section{Analisando as CRíticas ao Modelo CAPES de Avaliação}

As críticas identificadas na revisão da literatura e as constatações sobre os critérios utilizados na avaliação individual e dos programas levam às reflexões que seguem.

1.Heterogeneidade nas áreas do saber e nas instituições em relação aos recursos e às condições econômicas (SPAGNOLO; CALHAU, 2002). Considerando que o processo de avaliação adota como referência o padrão internacional do conhecimento na área, em vez de comparar a área de Administração, Ciências Contábeis e Turismo com as áreas de Física, Química, Medicina, seria mais adequado comparar cada área com o seu benchmark internacional. Por exemplo, as áreas de Administração, Ciências Contábeis e Turismo identificariam as melhores escolas do mundo e, ao final de cada triênio, fariam uma comparação do seu desempenho em relação ao desempenho destas escolas. 
2. As exigências por produção acadêmica resultaram em surto produtivista (KUENZER; MORAES, 2005): A indução para o aumento da produção científica fez com que o Brasil, em 2008, fosse responsável por cerca de $2 \%$ da produção científica internacional. Apesar deste baixo percentual, o Brasil assumiu a décima terceira posição no ranking mundial (FOLHA DE SÃO PAULO, 2010). Se forem mantidas, no triênio 2010-2012, as exigências da área de Administração, Ciências Contábeis e Turismo, a pontuação mínima a ser obtida com a produção científica será de 150 pontos. Isto significa que cada professor deverá publicar, por exemplo, um artigo por ano em revistas classificadas como Qualis B2 (50 pontos). Estima-se haver 1200 professores permanentes e uns 300 professores colaboradores na área. Caberia uma análise da capacidade de absorção desta produção pelas revistas da área e do percentual da produção científica da área, que é publicada em outras áreas e em revistas do exterior. Estes dados permitiriam uma avaliação mais precisa sobre a capacidade de escoamento, ou não, da produção da área.

3.Avaliação quantitativa da produção científica em detrimento de uma formação integral do pós-graduando (SGUISSARDI, 2006) - Os cursos de mestrado e doutorado em Administração são os principais formadores de professores para a graduação e pós-graduação em Administração. Embora alguns itens relacionados à formação do corpo discente já estejam presentes na ficha de avaliação dos programas, caberia uma reflexão na área a sobre formação integral dos pós-graduandos. Os programas estão formando adequadamente professores para a graduação e pós-graduação? Estão formando pesquisadores capazes de liderar grupos de pesquisa?

4.A avaliação deveria estar desvinculada das medidas de financiamento, premiação ou punição, e também da produção de rankings (DIAS SOBRINHO, 2003a). O atual modelo de avaliação tem como principal função o controle, a produção de rankings e não é um processo participativo. O preenchimento do Coleta CAPES é feito pelos coordenadores dos cursos, ou por pessoas especializadas nesta função. $\mathrm{O}$ corpo docente e discente é informado sobre prazos que devem ser cumpridos, pontos que devem ser obtidos e alguns outros critérios, mas, geralmente, não há envolvimento do corpo discente e docente no processo de avaliação e na análise dos resultados das avaliações. Seria desejável um processo de avaliação mais participativo, que ocorresse anualmente, pois o triênio é um período que não coincide com os dois anos dos alunos de mestrado ou os quatro anos dos alunos de doutorado. Uma meta anual, 
com envolvimento dos alunos, professores e pessoal técnicoadministrativo poderia ser mais desafiadora e menos estressante.

5.O modelo CAPES de avaliação está mais orientado para a pesquisa do que para a qualidade do ensino (MOREIRA; HORTALE; HARTZ, 2004).

A formação de doutores na sede, ou em doutorados fora da sede (Dinter), pode ser de boa qualidade e, geralmente, resulta em alto impacto social. Os egressos alavancam o crescimento de instituições de ensino em regiões carentes, com a criação de cursos de mestrado e doutorado próprios. Eles estabelecem vínculos da sua instituição com os seus orientadores e com grupos de pesquisa das instituições onde realizaram sua formação. Embora a CAPES estimule a melhor distribuição geográfica dos docentes doutores nas unidades da Federação, os seus critérios de avaliação não identificam estes impactos sociais. O processo de avaliação valoriza as publicações dos doutorandos, em coautoria, com seus orientadores, ou seja, se não houver artigos em coautoria, não haverá um "produto" e todo este processo não será valorizado na avaliação individual do orientador.

Analisando a produção científica dos doutores formados por bons programas de doutorado da área de Administração, Ciências Contábeis e Turismo, é possível constatar que muitos doutores não publicaram artigos em periódicos de alto impacto, em coautoria com seus orientadores. Quais as consequências desta decisão de valorizar o produto e não o processo? No médio e longo prazo, os candidatos que não apresentarem alto potencial de publicação não serão aceitos nos cursos de mestrado e doutorado. O processo de seleção será mais elitizado, reduzindo ainda mais as chances do candidato oriundo de instituições com pouca expressão, de regiões menos desenvolvidas, que não obteve a oportunidade de ser bolsista de iniciação científica e de conviver num grupo de pesquisa consolidado.

6.Organizar o programa conforme as regras do modelo da CAPES de avaliação (SPAGNOLO; CALHAU, 2002): Isto significa dizer que alguns programas estão se adaptando às regras para melhorar o seu conceito, e não necessariamente melhoria na qualidade ou no impacto social destes programas. Seguindo esta lógica, os programas poderão reduzir o número de ingressos, reduzir o número de professores e adotar outras medidas que melhorem os seus indicadores. Considerando, hipoteticamente, dois programas com 24 professores, o primeiro resolve descredenciar os 12 professores menos produtivos e os restantes 12 professores formam 12 doutores por ano (relação de um doutor por professor). O segundo 
programa mantém os 24 professores e forma 18 doutores por ano (relação de 0,75 doutores por professor). Uma análise quantitativa indicaria que o primeiro programa foi mais produtivo, mas, talvez, o impacto social tenha sido maior no segundo programa. E qual foi o impacto no desempenho e na produtividade e na motivação dos 12 professores do primeiro programa que foram descredenciados? Nas universidades não públicas, provavelmente estes professores seriam demitidos ou a sua carga horária seria reduzida. Nas universidades públicas, teriam um aumento da carga horária nos cursos de graduação e não receberiam mais os incentivos e oportunidades dadas aos professores da pós-graduação. Descredenciar estes professores, retirando a oportunidade de dar aula na pós-graduação, de ter orientandos, de receber incentivos e facilidades para a produção científica irá ajudá-los a retomar sua produtividade e a ser recredenciados? As universidades não estariam fazendo o contrário do que ensinam, ou seja, deveriam identificar aqueles com alguma dificuldade e apoiá-los, para que retomem sua produtividade?

7.A universidade tem como finalidade o desenvolvimento dos valores da sociedade; deve, portanto, ter uma avaliação que promova a reflexão e o questionamento (DIAS SOBRINHO, 2003). Considerando que as universidades formam os líderes da sociedade, o processo de avaliação deveria, de alguma forma, considerar o impacto na sociedade dos egressos e da universidade como instituição.

Os aspectos identificados na revisão da literatura e analisados nesta seção apontam para a necessidade de uma revisão nos critérios de avaliação da CAPES e dos programas de pós-graduação. Na próxima seção é apresentada uma proposta que busca um equilíbrio entre o produto e o processo, valorizando também outras atividades do professor.

\section{O FATOR "P"}

O Fator "P" é uma proposta desenvolvida pelo autor que, embora embrionária, amplia os quesitos do processo de avaliação individual. Fazendo uma analogia com aos "4 Ps" do marketing, poder-se-ia chamar o Fator "P" dos "4 Ps da avaliação": Produto, Praça, Professor e Pesquisador.

1.Produto: o artigo publicado em periódico é considerado o produto final, e será o item com maior peso na avaliação individual do professor. 
2.Praça: denomina-se "Praça" o âmbito ou o nível em que terão impacto as ações do indivíduo: (i) Nível local - o impacto no nível local será medido por meio da avaliação da produção científica que se restringe à cidade ou região: atividades em sala de aula, orientações presenciais, avaliações de artigos de periódicos locais e de monografias, dissertações e teses da sua instituição. Inserção social na região. Atividades administrativas e de representação na cidade e região. (ii) Nível Nacional - será considerado como impacto no nível nacional os pareceres ad hoc para instituições nacionais, avaliações de artigos para periódicos nacionais, dissertações e teses de outras instituições. Atividades de representação fora da sua região. Atividades em sala de aula em outras instituições e em cursos à distância. Atividades de inserção social, intercâmbio e de colaboração com instituições fora da sua região. (iii) Nível internacional - o impacto internacional será medido por meio da publicação de artigos em periódicos internacionais, interação com instituições no exterior, atividades em sala de aula no exterior, avaliação de artigos, dissertações e teses de instituições internacionais.

3.Professor: o terceiro "P" avalia o impacto do indivíduo enquanto docente. Neste "P" serão avaliadas: a qualidade das aulas, as orientações e as demais atividades docentes do professor. Será valorizada a sua capacidade de motivar e de facilitar a realização de estágios, intercâmbios e inserção social dos seus alunos.

4.Pesquisador: o quarto e último "P" refere-se aos impactos das atividades do indivíduo como Pesquisador. Serão avaliadas as atividades de pesquisa desenvolvidas por este indivíduo, como, por exemplo: projetos de pesquisas desenvolvidos, resultados obtidos, recursos obtidos, pessoas participantes do grupo de pesquisa e dos projetos etc.

$\mathrm{O} \mathrm{CNPq}$, para a avaliação dos candidatos à bolsa de produtividade, recomenda a adoção dos seguintes pesos: Produção Intelectual $(50 \%)$, formação de recursos humanos em nível de pósgraduação $(20 \%)$, coordenação ou participação em projetos de pesquisa (10\%), participação em atividades editoriais, de gestão científica, administração de instituições e núcleos de excelência científica e tecnológica $(5 \%)$; contribuição científica, tecnológica para a inovação $(5 \%)$ e liderança e reconhecimento institucional (10\%). A proposta do Fator "P" amplia os critérios indicados pelo $\mathrm{CNPq}$, pois considera também outras atividades não relacionadas à pesquisa e à produção científica e permite identificar o impacto das ações do professor nos níveis local, nacional ou internacional. Um professor com alto impacto local e nenhum impacto internacional não é importante para um programa 
de pós-graduação? No Fator "P" todas as atividades serão pontuadas e representarão um percentual do impacto total das atividades do indivíduo, conforme apresentado no Quadro2.

Quadro 2: Quesitos do Fator P

\begin{tabular}{|c|c|c|}
\hline Quesito & $\%$ & Descrição \\
\hline Produção científica & $50 \%$ & $\begin{array}{l}\text { Pontuada conforme os critérios da CAPES, } \\
\text { classificando e pontuando os artigos e livros numa } \\
\text { das tipologias: contribuição para resolver problemas } \\
\text { brasileiros ou contribuições para o avanço do } \\
\text { conhecimento na área no cenário internacional. }\end{array}$ \\
\hline Interação internacional & $10 \%$ & $\begin{array}{l}\text { Será avaliada em função dos resultados pessoais e } \\
\text { para o programa, sendo considerados o número de } \\
\text { visitantes recebidos, número de alunos e professores } \\
\text { do programa que fizeram intercâmbio, atividades } \\
\text { conjuntas realizadas etc. }\end{array}$ \\
\hline $\begin{array}{l}\text { Desempenho em sala de } \\
\text { aula ou em cursos à } \\
\text { distância }\end{array}$ & $10 \%$ & $\begin{array}{l}\text { Serão considerados todos os níveis (graduação, } \\
\text { cursos de extensão, cursos à distância, } \\
\text { especializações, mestrado, doutorado), medidos } \\
\text { pela avaliação dos alunos e pelo número de alunos } \\
\text { no período. }\end{array}$ \\
\hline Orientação de & $10 \%$ & $\begin{array}{l}\text { Serão considerados todos os níveis (graduação, } \\
\text { extensão, especialização, mestrado e doutorado, } \\
\text { com pesos distintos para cada nível. A avaliação } \\
\text { considerará um conjunto de critérios (prazo, } \\
\text { conceito final, número de orientandos, avaliação } \\
\text { dos orientandos, impacto dos trabalhos etc.) }\end{array}$ \\
\hline $\begin{array}{c}\text { Interação com a } \\
\text { sociedade e programas } \\
\text { emergentes }\end{array}$ & $10 \%$ & $\begin{array}{l}\text { Serão avaliadas em função do envolvimento do } \\
\text { professor, por critérios a serem definidos. }\end{array}$ \\
\hline $\begin{array}{l}\text { Avaliação de artigos, } \\
\text { monografias, } \\
\text { dissertações e teses }\end{array}$ & $5 \%$ & $\begin{array}{l}\text { Serão pontuadas conforme critérios a serem } \\
\text { definidos }\end{array}$ \\
\hline $\begin{array}{l}\text { Atividades } \\
\text { administrativas e de } \\
\text { representação }\end{array}$ & $5 \%$ & $\begin{array}{l}\text { Serão pontuadas conforme o tempo alocado e a } \\
\text { responsabilidade assumida pelo professor ao } \\
\text { desenvolver tais atividades. }\end{array}$ \\
\hline
\end{tabular}

\section{CONSIDERAÇõES Finais}

Para entender o quadro de mudanças que vem ocorrendo na carreira do professor, é preciso compreender que mudou o papel do professor de pósgraduação. Seu papel principal deixou de ser o de "mestre", da pessoa que ensinava e motivava seus alunos a apreender. $\mathrm{O}$ foco deixou de ser o ensino, a formação de pessoas e passou a ser a pesquisa e a divulgação 
dos seus resultados. A produtividade e a qualidade do trabalho do professor passaram a ser medidas pelo fator de impacto do periódico em que seu artigo foi publicado. Os impactos desta alteração de foco serão mais claramente percebidos ao longo do triênio 2010-2012, quando haverá uma mudança de comportamento dos professores em relação às atividades menos valorizadas. Se não forem tomadas medidas no sentido de valorizar as demais tarefas exercidas pelos professores, é provável que os programas e as universidades tenham dificuldade para encontrar voluntários para determinadas atividades.

Nas universidades públicas usa-se frequentemente a expressão: "se queres que alguma coisa aconteça, peça para quem não tem tempo". Isto significa dizer: dê mais trabalho para quem já trabalha bastante. Alguns professores trabalham 10, 12 ou 14 horas por dia, trabalham nos finais de semana e feriados, e, ao final da jornada, vão para a cama com a sensação de que trabalharam pouco, pois não atenderam todas as demandas.

Em palestras ministradas por representantes da CAPES, como a ministrada pelo Coordenador da Medicina II no Fórum Nacional de PósGraduação, vem sendo salientada a necessidade de "subir o sarrafo". Trata-se de uma metáfora para dizer que, à medida que certo número de pesquisadores atinge a produtividade esperada, as exigências são elevadas (Relatório do CBCE sobre o Fórum Nacional de Pós-Graduação, 2006).

A cobrança por aumento de produtividade será cada vez maior. A sobrecarga de trabalho de alguns é outra mudança que vem ocorrendo nos últimos anos, tendo consequências na saúde física e mental de vários professores.

É provável que seja cada vez menor o número de professores abnegados, aqueles que sempre estão dispostos a colaborar com a sua instituição. Estes professores costumam ter o seu trabalho enaltecido quando recebem as tarefas, quando assumem cargos burocráticos, quando são homenageados pelos alunos e pelos colegas, mas no momento das avaliações, se não publicarem papers nas revistas de alto impacto, serão considerados improdutivos.

Os próprios dirigentes da CAPES reconhecem que existe um uso inadequado do Qualis para a avaliação de professores e pesquisadores ou sobre as instituições universitárias (FOLHA DE SÃO PAULO, 2010). Por outro lado, as coordenações de programas de pós-graduação utilizam a pontuação do Qualis para credenciar e descredenciar professores para atender os critérios da CAPES. Como equacionar este problema?

Poder-se-ia dizer que as atividades de ensino e pesquisa devem ser complementares; ambas são importantes. No entanto, na prática, será que 
os professores alocarão seu tempo para o processo e as atividades que não valem pontos ou priorizarão o produto, que é o atestado de qualidade e de produtividade? É provável que o objetivo passe a ser a busca do melhor produto com a menor perda de tempo possível com o processo. Isto se obtém selecionando alunos com alto potencial para publicação. Esta política não está apenas redirecionando as atividades dos professores, mas também mudando o perfil dos alunos selecionados para os cursos de mestrado e doutorado. Cabe ressaltar que os dirigentes da CAPES, o membros do CTC, os coordenadores e integrantes das comissões que estabelecem os critérios e realizam as avaliações são colegas capacitados e dedicados que trabalham em prol do desenvolvimento da pós-graduação e merecem o nosso reconhecimento. As críticas realizadas por diversos autores e as deste artigo seguem os mesmos objetivos dos nossos colegas da CAPES, a elevação do padrão de qualidade da pós-graduação. Porém, questionam-se aqui algumas políticas que são adotadas sem uma avaliação profunda das suas consequências nos programas de pósgraduação.

Não se questiona a importância do produto, da publicação de artigos nos melhores periódicos científicos do mundo, mas as questões que ficam para a reflexão são:

a) Qual deve ser o peso atribuído para a produção científica na avaliação global do professor?

b) As atividades desejáveis de serem realizadas por um professor de pósgraduação (Quadro 1) não estão superdimensionadas?

c) A CAPES deve manter os atuais critérios de avaliação para o próximo triênio (2013-2015)?

d) Estaria na hora de uma reformulação na carreira universitária? Com base no exemplo de outros países, o Brasil deveria criar as carreiras de professor (com ênfase no ensino, tendo a pesquisa como atividade complementar) e a de pesquisador (ênfase na pesquisa, tendo o ensino como atividade complementar)?

e) Quem deveria tomar a iniciativa e promover este debate sobre estas questões na área de Administração: CAPES, ANPAD, ANGRAD, um fórum especial?

f) Ao partilhar estas inquietações, espero que elas provoquem reflexões nos leitores e nos colegas que nos representam e, se mais colegas partilharem destes sentimentos, que encontremos os meios para discutir e encaminhar estas questões. 


\section{REFERÊNCIAS}

BRASIL. Lei 5.540, de 28 de novembro de 1968. Fixa normas de organização e funcionamento do ensino superior e sua articulação com a escola média, e dá outras providências. Disponível em:

<http://www.fundata.org.br/Legislacao/Educacional/LEI005540_28_11_6 8.htm>. Acesso em: 14/12/2009.

CAPES - Critérios de Avaliação Trienal-2004-2007. Área de Avaliação: Administração/Turismo. Orientações do CTC - Reunião de 07/06/2006 - sobre a nova Ficha de Avaliação. 2006.

CAPES - Critérios do Qualis - Periódicos CAPES. Área de Administração, Ciências Contábeis e Turismo, julho de 2008.

CAPES. Webqualis. Disponível em:

<http://www.capes.gov.br/avaliacao/qualis>. Acesso em: 25/08/2010.

CAPES - Avaliação da Pós-graduação. Disponível em:

<www.capes.gov.br/avaliacao/avaliacao-da-pos-graduacao>. Acesso em: 25/08/2010.

$\mathrm{CNPq}$ - Conselho Nacional de Pesquisa Científica e Tecnológica. Bolsa de Produtividade - critérios de julgamento - CA-AE, vigência 2009-2011 Disponível em: <http://www.cnpq.br/cas/ca-ae.htm\#criterios>. Acesso em: 25/08/2010.

DIAS SOBRINHO, J. Avaliação: Políticas educacionais e reformas da educação superior. São Paulo: Cortez, 2003.

DIAS SOBRINHO, J. Avaliação da Educação Superior: regulação e emancipação. In: ; RISTOFF, D.I. (Org.). Avaliação e compromisso público: A educação superior em debate. Florianópolis: Insular, 2003a, p. 35-52.

FAPESP. O fôlego na berlinda. Disponível em: $<$ http://www.revistapesquisa.fapesp.br/?art=3602\&bd=1\&pg=2\&lg>. Acesso em: 27/10/2009.

Folha de São Paulo. "Uma mensagem a todos os membros de Pesquisa em Administração". Jorge Guimarães e Lívio Amaral. 27/10/2010. São Paulo, SP. 
HAMBURGER, E. Para quê pós-graduação? In: ANDRADE, M. de et al. Encontros com a Civilização Brasileira. Rio de Janeiro: Civilização Brasileira, 1980.

KUENZER, A.Z.; MORAES, M.C.M.de. Temas e tramas na pósgraduação em educação. Educação e Sociedade, v. 26, n. 93, p. 13411362, 2005.

MOREIRA, C. O.F.; HORTALE, V. A.; HARTZ, Z. de A. Avaliação da pós-graduação: buscando consenso. Revista Brasileira de PósGraduação, v. 1, n. 1, p. 26-40, 2004.

Relatório do CBCE sobre o Fórum Nacional de Pós-Graduação. Evento realizado em Brasília, entre 3 e 5 de maio de 2006. Disponível em: $<$ http://boletimef.org/forum/viewtopic.php?f=6\&t=10 >. Acesso em: 28/10/2010.

SGUISSARDI, V. A avaliação defensiva no "modelo CAPES de avaliação" - É possível conciliar avaliação educativa com processos de regulação e controle do Estado? Perspectiva, v. 24, n. 1, p. 49-88, 2006.

SPAGNOLO, F.; CALHAU, M.G. Observadores internacionais avaliam a avaliação da CAPES. Infocapes, v. 10, n. 1, p. 7-34, 2002.

\section{DAdOS DOS AUTORES}

LUIS FELIPE NASCIMENTO (nascimento@ea.ufrgs.br)

Formação: Graduação em Engenharia Elétrica (UFSM), Mestrado em Engenharia de Produção (UFSM) e Doutorado em Economia e Meio Ambiente pela Kassel University - Alemanha.

Instituição de vinculação: Universidade Federal do Rio Grande do Sul Porto Alegre/RS - Brasil

Áreas de interesse em pesquisa: Educação para a Sustentabilidade e Gestão Sustentável de Cadeias de Suprimento.

Recebido em: 27/01/2010 • Aprovado em: 30/10/2010 